\title{
Current state of care for pediatric ACL- ruptures in the Netherlands: a survey
}

M. Dietvorst*, MD, department of orthopaedic surgery, Máxima Medical Center, Eindhoven, The Netherlands; martijndietvorst@gmail.com; +31 611916004

M. Reijman, PhD, department of orthopaedic surgery, Erasmus MC, University Medical Centre Rotterdam, Rotterdam, The Netherlands; m.reijman@erasmusmc.nl

R. van Zutven, MSc, department of orthopaedic surgery, Máxima Medical Center, Eindhoven, The Netherlands; MAIL

M.P.J. van den Bekerom, MD, department of orthopaedic surgery, Onze Lieve Vrouwe Gasthuis, Amsterdam, The Netherlands; m.p.j.vandenbekerom@olvg.nl

D.E. Meuffels, MD PhD, department of orthopaedic surgery, Erasmus MC, University Medical Centre Rotterdam, Rotterdam, The Netherlands; d.meuffels@erasmusmc.nl

M.P. Somford, MD PhD, department of orthopaedic surgery, Rijnstate Hospital, Arnhem, The Netherlands; $\underline{\mathrm{mp} \text { somford@hotmail.com }}$

R.P.A. Janssen, MD PhD, department of orthopaedic surgery, Máxima Medical Center, Eindhoven, The Netherlands; r.janssen@mmc.nl

* corresponding author 


\begin{abstract}
Purpose

The purpose of this survey is to inventory the current state of care for pediatric anterior cruciate ligament $(A C L)$ injuries in the Netherlands.

\section{Methods}

The survey was conveyed by email among all members of the Dutch Arthroscopy Society (NVA) and promoted on the website of the NVA. It was developed by the scientific committee of the NVA by a consensus meeting discussing relevant topics in pediatric $\mathrm{ACL}$ injuries.
\end{abstract}

\title{
Results
}

All members of the NVA received the survey $(n=540)$. A total of $158(29 \%)$ members responded to the survey, of which 143 were fully completed. Fifteen of the 158 respondents did not complete the survey due to the fact that the surgeons did not perform ACL reconstructions. A total of 126 responses were analysed, after exclusion of anonymous responses and responses of trainees or physician assistants. The main finding of this survey is that $78 \%$ of the respondents tend to treat children with open physes non-operatively, while $65 \%$ tend to treat children with closed physes operatively. The most frequently performed procedure is the transphyseal reconstruction. Many considerations were involved in choosing operative treatment, of which concomitant injury of the menisci or ligaments were most frequently reported. The postoperative follow-up period varies from less than 1 year (24\%) until fully grown (27\%). Approximately one third of the respondents did not give an indication of the follow-up period.

\section{Conclusion}

This survey shows that the current state of care for pediatric $A C L$ injuries is variable and a matter of debate in the Netherlands. Children with open physes tend to be treated non-operatively, while children with closed physes are operated more frequently. In case of an operative treatment in a child with open physes, a transphyseal $\mathrm{ACL}$ reconstruction is most frequently performed. There is variation in the postoperative follow-up period. To gain information on future treatment results, a registry should be developed.

Level of evidence $V$

\section{Keywords}

"ACL", "Reconstruction", “Pediatric", “Physeal sparing”, "Transphyseal”, “Non-operative”, "Questionnaire", "Survey" 


\section{Introduction}

The management of anterior cruciate ligament $(\mathrm{ACL})$ injuries in the skeletally immature patient is an area of controversy.[1,22] Both operative and non-operative treatment can result in complications, such as physeal damage resulting in growth disturbances postoperatively or secondary damage to the meniscus or cartilage in case of non-operative treatment. Opinions on whether pediatric ACL injuries should primarily be treated operatively or non-operatively are still divided.[11,16,24] Should all children with open physes be treated non-operatively until the physes are closed or is surgical treatment a viable option in skeletally immature children? In case of operative treatment, which surgical technique should be used to ensure optimal biomechanical positioning of the graft and to prevent physeal injury and graft failure? Which considerations play a role in indicating surgical treatment? What are the formats and requirements for follow-up? All these items are a matter of debate due to a lack of solid scientific knowledge.[11]

During the past two decades, there is an increasing number of studies on ACL-injuries in skeletally immature children.[16] These studies suggest an increase in the incidence of ACL injury in children, which however has not been determined by epidemiological studies.[19] It may therefore be caused by an increase in awareness and advances in diagnostics.[19]

Studies on the management of children with ACL injury present a low level of evidence.[18] The gold standard of management of skeletally immature children with an ACL-rupture has still to be determined and therefore "the best treatment" for the individual skeletally immature patient is so far unknown.[22] Treatment algorithms for ACL ruptures in skeletally immature children vary around the world and are mainly experience-based.[4,10,19,24,25]. With the possible increasing numbers of these injuries and the dilemma that exists between reconstruction and avoidance of physeal injury, an evidence based approach of this topic is needed.[13,22]

This study aims to inventory the current state of care for paediatric ACL-ruptures in the Netherlands by conducting a survey among members of the Dutch Arthroscopic Association. The ESSKA paediatric anterior cruciate ligament monitoring initiative created by their international survey awareness on the diversity in clinical practice and the authors hoped that it could serve as a catalyst for international collaborations.[19] The outcomes of this survey can also be used to monitor and give direction to future standards of treatment in the Netherlands. The current national guidelines on $\mathrm{ACL}$ injury and treatment in the Netherlands did not include paediatric ACL injuries. The hypothesis therefore is that treatment for skeletally immature children with an ACL injury is heterogeneous.

\section{Materials and methods}

\section{Survey administration}

The survey was administrated by email to all members of the Dutch Arthroscopy Society (Nederlandse Vereniging van Arthroscopie (NVA)). The Dutch Arthroscopy Society has 540 members, mainly orthopaedic surgeons but also including specialists such as plastic surgeons and veterinarians who do not treat ligament injuries of the knee. Only orthopaedic surgeons are included in the analysis of this survey. A reminder was sent to the members of the NVA that did not respond to the first request to fill in the survey. Besides, the survey was promoted on the website of the NVA (https://scopie.org/site/). The responses were analysed on May $1^{\text {st }} 2017$. 


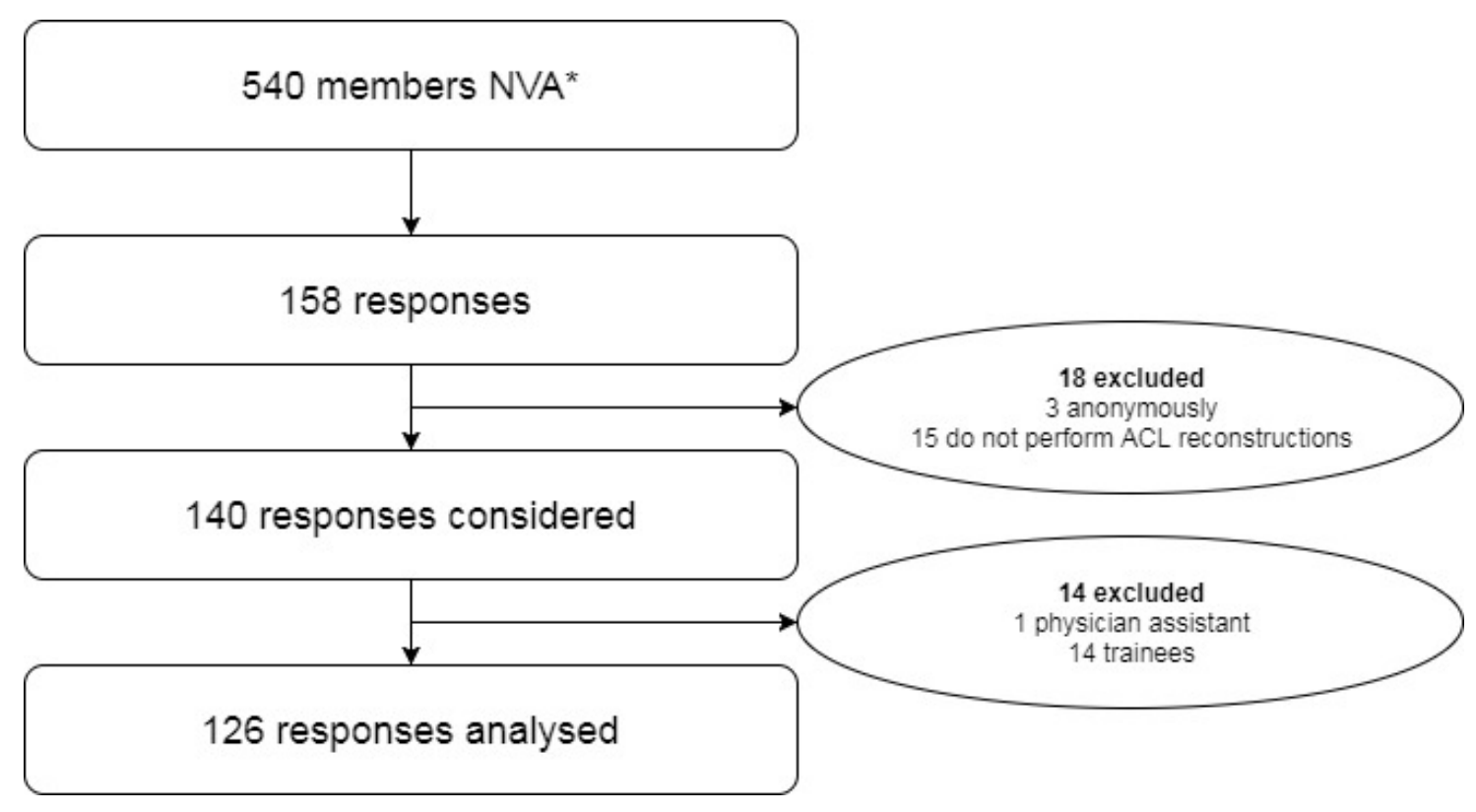

Figure 1. Flowchart of responses to survey of the NVA (*Dutch Arthroscopic Society).

\section{Survey development}

The scientific committee of the NVA developed the survey by consensus meeting on the relevant topics in pediatric ACL. The scientific committee of the NVA consist of 4 experienced arthroscopic orthopaedic surgeons and one clinical epidemiologist and scientific researcher in the field of ACL ruptures. The survey was constructed by a Delphi method and all members approved the final version of the survey (see appendix 1 ). In the final survey the following topics are included: amount of consultations and reconstructions, management of children with open and closed physes, advices regarding sports, indications for operative treatment, surgical techniques and postoperative followup. 


\section{Results}

A total of 540 surveys were sent to all members of the NVA. $158(29 \%)$ members responded on the survey, of which 140 were considered for analysis. After exclusion, 126 responses were included for analysis as is shown in figure 1.

\section{"How many consultations and reconstructions are yearly performed?"}

The number of yearly performed ACL-reconstructions in general (regardless of age) are shown in Table 1 . The number of consultations by children in general and by children with open physes are shown in Table 2 and 3.

Table 1. Number of yearly performed ACL reconstructions in general $(n=126)$.

$\begin{array}{cc}\mathbf{A C L} \text { reconstructions per year, } \mathbf{n} & \text { Number (\%) } \\ <20 & 38(30) \\ 20 \text { to } 50 & 39(31) \\ >50 & 48(38) \\ \text { Unknown } & 1(1)\end{array}$

Table 2. Number of consultations of children (including children with open and closed physes) with ACL injury per year ( $n=126)$.

$\begin{array}{cc}\text { Consultations per year, } \mathbf{n} & \text { Number (\%) } \\ <10 & 64(51) \\ 10 \text { to } 50 & 56(44) \\ >50 & 4(3) \\ \text { Unknown } & 2(2)\end{array}$

Table 3. Number of consultations of children with open physes with ACL injury per year $(n=126)$.

$\begin{array}{cc}\text { Consultations per year, } \mathbf{n} & \text { Number (\%) } \\ <10 & 100(79) \\ 10 \text { to } 50 & 23(18) \\ >50 & 2(2) \\ \text { Unknown } & 1(1)\end{array}$

\section{"How is the management of pediatric ACL injuries?"}

In case of open physes, $78 \%$ of the children with open physis are primarily treated non-operatively and $22 \%$ operatively. In children with a closed physes, $35 \%$ are treated primarily non-operatively and $65 \%$ operatively.

In case of non-operative treatment, the respondents gave different recommendations regarding sports participation (more than one answer allowed). Ranked on frequency, $70 \%(n=88)$ of the 
respondents recommends to adjust the type of sports, $41 \%(n=51)$ the level of sports, $43 \%(n=54)$ to wear a brace during sports and $6 \%(n=8)$ to stop sports participation.

\section{"In case of a concomitant symptomatic meniscal tear, does this influence the} decision making in conservative treatment?"

In case of a concomitant, symptomatic meniscal tear, $25 \%(n=32)$ of the respondents stated that this would not influence treatment. $73 \%(n=92)$ responded that this would influence the choice of treatment, of which $5 \%(n=5)$ refers to another specialist, $13 \%(n=12)$ performs an ACL reconstruction, $30 \%(n=28)$ performs a meniscal repair and $52 \%(n=47)$ performs an $A C L$ reconstruction and meniscal repair. Two (2\%) respondents did not fill in an answer to this question.

\section{"Which factors are considered important as indication for surgical treatment?" \\ Different considerations ranked on importance are shown in Table 4.}

Table 4. Considerations concerning indications for operative treatment, more than one answer per respondent allowed.

$\begin{array}{lc}\text { Considerations } & \text { Number (\%) } \\ \text { Concomitant ligament injury } & 89(71) \\ \text { Concomitant meniscal injury } & 88(70) \\ \text { Age of child } & 74(59) \\ \text { Wish to perform sports } & 72(57) \\ \text { Type of sport participation } & 62(49) \\ \text { Level of sport participation } & 58(46) \\ \text { Preference of parents } & 15(12) \\ \text { Degree of instability } & 8(6.3)\end{array}$

\section{"Which surgical techniques are performed in children with open physes?"} Of the 126 respondents, 87 (69\%) responded to this question in which more than one answer was allowed. In children with open physes, $64 \%(n=56)$ of the respondents perform a transphyseal reconstruction, $28 \%(n=24)$ a physeal sparing reconstruction, $20 \%(n=17)$ a transtibial and femoral physeal sparing procedure and $11 \%(n=10)$ an extra-articular procedure.

\footnotetext{
"In case of an ACL reconstruction of children with open physes, what is the duration of the follow-up period?"

Of the 126 respondents, $27 \%$ ( $n=34)$ follow the children until skeletal maturity, 25\% ( $n=32)$ for 1 year postoperatively, $7 \%(n=9)$ for 1 to 2 years postoperatively and $6 \%(n=8)$ for more than 2 years postoperatively. A total of $34 \%(n=43)$ did not complete this question or indicated that the mean follow-up was unknown.
} 


\section{Discussion}

The most important finding of this survey is that the majority of the children with open physes are treated non-operatively, while most children with closed physes are treated operatively. In case of operative treatment in a child with open physes, $64 \%$ of the respondents chose to perform a transphyseal procedure. Another important finding is that many considerations are involved in indicating operative treatment, of which concomitant injury of the menisci or ligaments are most frequently reported.

The majority of the respondents treat less than 10 children with an ACL injury per year, and only $3 \%$ of clinicians are consulted by more than 50 children per year. Based on these data, one can calculate that there are several hundred $\mathrm{ACL}$ injuries in children per year in the Netherlands. The exact incidence of $A C L$ injury in children in the Netherlands is unknown however and there might be a possibility of overestimation of the number of consultations in this survey.

Non-operative treatment is the preferred treatment in skeletally immature injured children for $78 \%$ of the respondents. Within the pediatric orthopaedic community, opinions are divided whether pediatric ACL injuries should be treated non-operatively or operatively.[15,25] Comparing two previous surveys from 2002 and 2015, the proportion (34\% versus 59\%) of orthopaedic surgeons who advocate operative treatment has almost doubled.[12,19] In a recent survey by the PRiSM (Pediatric Research in Sports Medicine) society, a case of a 8-year old child with a complete ACL rupture was presented to the respondents. In this survey, only $3 \%$ would treat the child non-operatively.[23] Reasons for this increase are development of surgical techniques and a stronger belief in beneficial results from surgical treatments.[19] However, the evidence is low; there are no high level evidence studies nor studies that compared results from the past to results from the present.[18,19] In decision making, weighing risks and benefits between primary non-operative and primary operative treatment is crucial.[17].

According to current survey, the most important considerations for operative treatment were concomitant ligament and meniscus injury, followed by the age of the child, the wish to continue to perform sports and the type and level of sports participation. The preference of the parents and the degree of instability were deemed less relevant. A consensus meeting of the International Olympic Committee in 2018 stated that there are three indications for ACL reconstruction: repairable concomitant injury that require surgery, recurrent and symptomatic giving way after completing rehabilitation or unacceptable participation restrictions.[1] It is generally accepted that operative treatment reduces the risk of further damage of the menisci or cartilage in case of persistent instability.[7,11] Non-operative or delayed operative treatment ( 3 to 12 months after trauma) may lead to meniscal injury, due to persistent instability. $[10,11,14]$ In conclusion, the goal of operative treatment is to restore stability and protect the knee against future meniscal or chondral lesions.[11] Besides, the wish to return to pre-trauma level and type of sport might be important considerations for operative treatment.[1,5]

In case of non-operative treatment, the majority of the respondents advocated adjusting the type of sports to avoid pivoting sports. Recent literature suggests that rehabilitation after ACL injury in children is mainly focussed on neuromuscular stimulation and multi-joint functional stability and less on muscular strength and hypertrophy. $[1,8,17,20]$ In the beginning, children should be guarded from performing pivoting activities and advised to wear a brace in sport.[20] Although there are no solid 
studies on bracing children after ACL injury, a small majority advises to use a brace during sports participation. $[1,20]$ In this survey, the recommendations of the respondents adhere to the current limited scientific evidence for non-operative treatment.

In case of operative treatment, most of the respondents perform a transphyseal repair. Different surgical techniques have been developed to address postoperative complications such as growth disturbances and graft failure.[9,22] A recent systematic review of Pierce et al. concluded that there is no difference in clinical outcome in regard to growth disturbances and re-rupture rate between transphyseal and physeal sparing procedures.[22] Theoretical advantages of a transphyseal procedure are a more anatomic $A C L$ reconstruction and more familiarity among surgeons compared to a physeal sparing procedure.[22] One must note however, the results of the pooled data were weakened by lack of uniformity among the compared studies.[11,22] To date, there is no convincing evidence to support a specific procedure for paediatric $A C L$ reconstruction.[11,22]

There is a variety in the duration of follow-up after $A C L$ reconstruction among respondents in this survey. A third of the respondents did not respond to this item. The follow-up until skeletal maturity is performed by $27 \%$ of the respondents. Twenty-five percent of the respondents have a follow-up of less than one year postoperatively. These outcomes are similar to the findings in the ESSKA monitoring initiative survey.[19] It is noticeable that most respondents do not follow the children until fully grown considering the risks of postoperative growth disturbances or graft failure.[19]

A limitation of this survey is the low response rate of $29 \%$ (158/540). This response rate is higher compared to a response rate of $22 \%$ in the ESSKA survey, but the total amount of respondents in ESSKA survey was 491.[19] In contrast to the ESSKA survey, only the responses of orthopaedic surgeons were analysed in this survey and the responses of trainees were excluded. Despite the response rate, the results of this study may provide a better view on the current state of care in the Netherlands.

The questions in this survey are meant to evaluate the treatment of skeletally immature children in general. There is no further specification of the child besides the open physes. For example, one might consider using different surgical techniques based on the estimation of residual growth. Since these questions give an indication of the general treatment of children with open physes, a limitation is that these questions are not case specific and might therefore only give an indication of the techniques which are being used in the Netherlands.

Another limitation of this survey is that the use of patient reported outcome measures (PROMs) is not evaluated. PROMs should be used to gain insight in patient's perceived treatment results. $[2,3,6]$ In the ESSKA survey, all respondents used PROMs, however only $15 \%$ used child friendly questionnaires.[19] In a recent systematic review, Dietvorst et al showed that the use of adults PROMs in children should be avoided.[6] As the use of PROMs is not evaluated in this survey, no conclusion can be drawn about the use of these PROMs in the Netherlands.

Further research should aim at creating an evidence based, skeletal age specific treatment algorithm. This requires high level studies on non-operative and operative treatment in pediatric $A C L$ injuries. Different operative techniques should be evaluated and developed, in order to minimize graft failure and growth disturbances. Determination of the duration and methods for follow-up must also be 
established. To evaluate future results of $A C L$ reconstructions in children, there is a necessity for a registry to gain information on outcomes.

\section{Conclusion}

This survey shows that the current state of care for paediatric ACL injuries is variable and a matter of debate in the Netherlands. Children with open physes tend to be treated non-operatively, while children with closed physes are operated more frequently. In case of an operative treatment in a child with open physes, a transphyseal ACL reconstruction is most frequently performed. There is variation in the postoperative follow-up period. Further research should be aimed at creating an age specific treatment algorithm and (inter)national guidelines should be developed. To gain information on future treatment results, a registry should be developed. 


\section{List of abbreviations}

$\mathrm{ACL}$; anterior cruciate ligament

ESSKA; European Society for Sports Traumatology, Knee Surgery and Arthroscopy

NVA; Nederlandse Vereniging voor Arthroscopy (Dutch Arthroscopy Society)

PRiSM; Pediatric Research in Sports Medicine

PROMs; Patient Reported Outcome Measures

\section{Conflict of interests}

The authors declare that they have no competing interests.

\section{Funding}

No financial support was received for this study. This survey is an initiative of the NVA scientific committee.

\section{Ethical approval}

This survey was conducted according to appropriate ethical standards.

\section{Author contributions}

M. Dietvorst: corresponding author and statistical analysis

M. Reijman: initiative and development of the survey, statistical analysis, and critical revision of the article

R. van Zutven: statistical analysis

M.P.J. van den Bekerom: initiative and development of the survey and critical revision of the article

D.E. Meuffels: initiative and development of the survey and critical revision of the article M.P. Somford: initiative and development of the survey and critical revision of the article

R.P.A. Janssen: initiative and development of the survey, critical revision of the article. 


\section{References}

1. Ardern CL, Ekås G, Grindhem H, Moksnes H, Anderson AF, Chotel F, Cohen M, Forssblad M, Ganley TJ, Feller JA, Karlsson J, Kocher MS, LaPrade RF, McNamee M, Mandelbaum B, Micheli L, Mohtadi N, Reider B, Roe J, Seil R, Siebold R, Silvers-Granelli HJ, Soligard T, Witvrouw E, Engebretsen L (2018) 2018 International Olympic Committee consensus statement on prevention, diagnosis and management of paediatric anterior cruciate ligament ( $A C L$ ) injuries. JISAKOS 0:1-17 [Epub ahead of print]

2. Brusalis CM, Lakomkin N, Suryavanshi JR, Cruz Al Jr, Green DW, Jones KJ, Fabricant PD (2017) Clinical Outcome Reporting in Youth ACL Literature Is Widely Variable. Orthop J Sports Med 11;5(8):2325967117724431

3. Chen J, Ou L, Hollis SJ (2013) A systematic review of the impact of routine collection of patient reported outcome measures on patients, providers and health organisations in an oncologic setting. BMC Health Serv Res 13:211

4. Chotel F, Seil R (2013) Growth disturbances after transphyseal ACL reconstruction in skeletally immature patients: who is more at risk? Young child or adolescent? J Pediatr Orthop 33(5):585586

5. Daniel DM, Fithian DC (1994) Indications for ACL surgery. Arthroscopy 10(4):434-441

6. Dietvorst M, Reijman M, van Groningen B, van der Steen MC, Janssen RPA (2017) PROMs in paediatric knee ligament injury: use the Pedi-IKDC and avoid using adult PROMs. Knee Surg Sports Traumatol Arthrosc, 1-9

7. Dunn WR, Lyman S, Lincoln AE, Amoroso PJ, Wickiewicz T, Marx RG (2004) The effect of anterior cruciate ligament reconstruction on the risk of knee reinjury. Am J Sports Med 32(8):1906-1914

8. Faigenbaum AD, Kraemer WJ, Blimkie CJ, Jeffreys I, Micheli L, Nitka M, Rowland TW (2009) Youth resistance training: updated position statement paper from the national strength and conditioning association. J Strength Cond Res 23:S60-S79

9. Faun $\varnothing$ P, Rahr-Wagner L, Lind M (2014) Risk for revision after anterior cruciate ligament reconstruction is higher among adolescents: results from the Danish registry of knee ligament reconstruction. Orthop J Sports Med 2(10):2325967114552405

10. Henry J, Chotel F, Chouteau J, Fessy MH, Bérard J, Moyen, B (2009) Rupture of the anterior cruciate ligament in children: early reconstruction with open physes or delayed reconstruction to skeletal maturity? Knee Surg Sports Traumatol Arthrosc 17(7):748-755

11.Janssen RPA, Lind M, Engebretsen L, Seil R, Moksnes H, Faun $\varnothing$ P, Murray M (2018) Pediatric ACL injuries: Treatment and Challenges. In: Kerkhoffs GMMJ, Haddad F, Hirschmann M, Karlsson J, Seil R (eds) ESSKA Instructional Course Lecture Book. Springer, Heidelberg, p241-259

12.Kocher MS, Saxon HS, Hovis WD, Hawkins RJ (2002) Management and complications of anterior cruciate ligament injuries in skeletally immature patients: survey of the Herodicus Society and The ACL Study Group. J Pediatr Orthop 22(4):452-457

13. Mall NA, Paletta GA (2013) Pediatric ACL injuries: evaluation and management. Curr Rev Musculoskelet Med 6(2):132-140

14.Mansson O, Sernert N, Rostgard-Christensen L, Kartus J (2015) Long-term clinical and radiographic results after delayed anterior cruciate ligament reconstruction in adolescents. Am J Sports Med 43:138-145

15. Moksnes H, Engebretsen $L$ (2015) It takes more than timing: Letter to the editor. Am J Sports Med 43:NP14-15 
16. Moksnes H, Engebretsen L, Eitzen I, Risberg MA (2013) Functional outcomes following a nonoperative treatment algorithm for anterior cruciate ligament injuries in skeletally immature children 12 years and younger. A prospective cohort with 2 years follow-up. Br J Sports Med 47:488-494

17. Moksnes H, Engebretsen L, Risberg MA (2012) Management of anterior cruciate ligament injuries in skeletally immature individuals. J Orthop Sports Phys Ther 42(3):172-183

18. Moksnes H, Engebretsen L, Risberg MA (2012) The current evidence for treatment of ACL injuries in children is low: a systematic review. J Bone Joint Surg Am 94(12):1112-1119

19. Moksnes H, Engebretsen L, Seil R (2016) The ESSKA paediatric anterior cruciate ligament monitoring initiative. Knee Surg Sports Traumatol Arthrosc 24(3):680-687

20.Moksnes H, Grindem H (2016) Prevention and rehabilitation of paediatric anterior cruciate ligament injuries. Knee Surg Sports Traumatol Arthrosc 24(3):730-736

21.Peterson DC, Ayeni OR (2016) Pediatric anterior cruciate ligament reconstruction outcomes. Curr Rev Musculoskelet 9(4):339-347

22.Pierce TP, Issa K, Festa A, Scillia AJ, McInerney VK (2017) Pediatric anterior cruciate ligament reconstruction: a systematic review of transphyseal versus physeal-sparing techniques. Am J Sports Med 45(2):488-494

23.Popkin CA, Wright ML, Pennock AT, Vogel LA, Padaki A, Redler LH, Ahmad CS (2018) Trends in Management and Complications of Anterior Cruciate Ligament Injuries in Pediatric Patients: A Survey of the PRiSM Society. J Pediatr Orthop 38(2):e61-e65

24.Reider B (2015) A matter of timing. Am J Sports Med 43:273-274

25.Yoo WJ, Kocher MS, Micheli $\amalg$ (2011) Growth plate disturbance after transphyseal reconstruction of the anterior cruciate ligament in skeletally immature adolescent patients: an MR imaging study. J Pediatr Orthop 31(6):691-696 